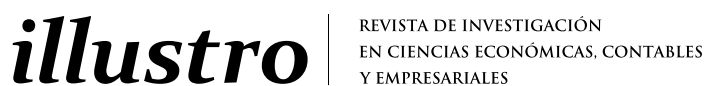

\title{
Migrantes venezolanos en Arequipa: motivación y proyecto migratorio
}

\author{
Venezuelan migrants in Arequipa: motivation \\ and migration project
}

\author{
Patricio Manolo Cárdenas Hinojosa \\ Universidad Carlos III de Madrid, Madrid, España•pcardenash@unsa.edu.pe \\ Oswaldo José Moreno \\ Universidad Carlos III de Madrid, Madrid, España • oswmoreno@gmail.com \\ Anatolia Hortencia Hinojosa Pérez \\ Universidad Católica San Pablo, Arequipa, Perú • hhinojosa@ucsp.edu.pe
}

\section{Resumen}

La presente investigación se realizó con la finalidad de profundizar en las características y motivaciones del flujo migratorio de venezolanos en la ciudad de Arequipa, Perú. En este sentido, se describen aspectos socioeconómicos de Venezuela y Perú como posibles fuentes de motivación y expulsión para el migrante venezolano en la ciudad de Arequipa, y se analiza la trayectoria y proyecto migratorio del migrante venezolano en la ciudad de Arequipa. Se observa que, si bien las condiciones de precariedad de la situación económica de Venezuela propician la migración hacia distintos destinos en América Latina, también se confirma que las redes migratorias y las familias permiten condicionar un proyecto migratorio en el que se sopesan los costos de traslado y la adaptación a la ciudad de destino.

Palabras clave: motivación, proyecto migratorio, migrantes venezolanos. 


\begin{abstract}
This research was carried out in order to delve into the characteristics and motivations of the migratory flow of Venezuelans in the city of Arequipa, Peru. To this end, socioeconomic aspects of Venezuela and Peru are described as possible sources of motivation and expulsion for the Venezuelan migrant in the city of Arequipa, and the trajectory and migratory project of the Venezuelan migrant in the city of Arequipa is analyzed. It is observed that, although the precarious conditions of the economic situation in Venezuela favor migration to different destinations in Latin America, it is also confirmed that migratory networks and families make it possible to condition a migratory project in which are weighed transfer costs and adaptation to the city of destination.
\end{abstract}

Keywords: motivation, migratory project, Venezuelan migrants.

\title{
1. Introducción
}

El fenómeno migratorio que se suscita en la actualidad en distintos países de Latinoamérica, sobre todo en el sur del Pacífico, por parte de migrantes de nacionalidad venezolana ha sido de tan notable extensión, que los países de mayor proximidad territorial han desarrollado políticas migratorias, por un lado, ajustadas al derecho internacional y, por otro, aspirando a una captación de fuerza laboral en edad productiva y alto perfil educativo, de una manera mucho más organizada.

Desde el punto de vista de la legislación peruana, en lo que se refiere a políticas en materia migratoria, existe la figura del permiso temporal de permanencia (PTP), aprobado por el presidente Pedro Pablo Kuczynski, vía decreto supremo No 001-2018-IN, el cual establecía los lineamientos a seguir por parte de la población venezolana residente en Perú para optar a dicha condición. Esta legislación fue modificada mediante el decreto supremo $\mathrm{N}^{\circ}$ 007-2018-IN, por el presidente Martín Vizcarra; en líneas generales, la modificación correspondió principalmente al plazo de vencimiento para la presentación de solicitud del 30 de junio de 2019 al 31 de diciembre de 2018.
Desde una perspectiva económica, Perú, como país receptor y de atracción, ostenta periodos de crecimiento de la economía debido a la aplicación de políticas macro, con factores de confianza como el Banco Central de Reserva del Perú (BCRP). Se trata de factores de atracción que podrían haber sido tomados en cuenta por los migrantes venezolanos para optar por la opción de emigrar hacia Perú. Aunado a ello, Venezuela presenta una marcada crisis económica y social, con un declive pronunciado desde el año 2015.

Izquierdo Escribano (2000) define el proyecto migratorio como «el proyecto de las gentes que se mueven, se nutre de los motivos para irse de un lugar y de las razones para quedarse en otro» (p. 228). En la literatura se encuentran estudios sobre el flujo migratorio a Lima, la ciudad con la mayor afluencia de migrantes venezolanos en Perú. Sin embargo, el estudio de los flujos migratorios a ciudades intermedias, como Arequipa, ha sido descuidado por la literatura, pese a ser la segunda ciudad de mayor tamaño en el país.

En este sentido, la pregunta que guía este trabajo es la siguiente: ¿cuáles son las moti- 
vaciones del flujo migratorio de venezolanos en la ciudad de Arequipa, Perú?

Los objetivos propuestos son los siguientes:

- Describir aspectos socioeconómicos de Venezuela y Perú como posibles fuentes de motivación y expulsión para el migrante venezolano en la ciudad de Arequipa.

- Analizar la trayectoria y proyecto migratorio del migrante venezolano en la ciudad de Arequipa.

El artículo se organiza de la siguiente manera. La segunda sección presenta una descripción de variables económicas y sociales de Perú como país atractivo para emigrar. La tercera sección presenta las variables económicas y sociales de Venezuela, como país emisor y expulsor. La cuarta sección presenta el marco teórico y la revisión de la literatura, desde el punto de vista de la economía como ciencia que estudia el fenómeno migratorio. La quinta sección presenta el método. La sección seis presenta los resultados de las entrevistas. La sección siete presenta la discusión. Finalmente, la sección ocho concluye.

\section{Perú, tierra de oportunidades}

En cuanto a condiciones económicas que pudieron propiciar una mirada hacia el país por parte de migrantes de nacionalidad venezolana para gestionar un proyecto migratorio, se analiza el producto interno bruto (PIB), las acciones de políticas macroeconómicas y las políticas de migración.

\section{Variables macroeconómicas}

Chacaltana (2016) señala que, en el periodo 2002-2013, Perú fue el segundo país de América
Latina con mayor crecimiento, con una tasa de $6 \%$ anual, durante más de una década, con excepción de los años de crisis financiera mundial, 2008-2009. Gutiérrez y Pérez (2018) señalan que en la estructura productiva de la economía peruana prevalecen los sectores no primarios, manufactura no primaria, electricidad, construcción, comercio y servicios, con un $75.6 \%$ de participación en el PIB.

Sobre el contexto laboral y económico, Koechlin y otros (2019) señalan que Perú venía de un periodo de crecimiento de $6.5 \%$ anual del PIB entre el 2003 y 2014, lo que generó una percepción regional positiva sobre el desempeño de la economía peruana, incluyendo el eslogan del «milagro peruano», promovido desde sectores gubernamentales y mediáticos.

Rossini (2016) refiere que el periodo de estabilidad en Perú fue consecuencia de una serie de estrategias con objetivos precisos. Desde un contexto económico favorable, también se considera como premisa fundamental el factor confianza, con una percepción positiva por parte de inversionistas foráneos. En este sentido, con relación al Banco Central de Reserva del Perú (BCRP), Pérez, Quispe y Rodríguez (2016) sostienen que su autonomía viene a quedar circunscrita por un marco institucional que establece claramente un objetivo único de estabilidad monetaria y «que permite el libre diseño de su política, la elección del instrumento y del momento más apropiado de su implementación» (p. 66).

Otro aspecto de políticas macro es la paulatina desdolarización de la economía, con procesos importantes de dotación de una moneda nacional para la población que cumpla con sus funciones dinerarias en condiciones similares al dólar. Sobre este punto, Armas (2016) sostiene 
que «cuando la moneda nacional es percibida como fuerte, respaldada por un banco central fiable, y goza además de estabilidad macro-financiera, los agentes tienen incentivos para usarla en sus transacciones financieras y económicas» (p. 94).

El clima de relativa estabilidad económica y el crecimiento de la economía de Perú podrían haber sido tomados en consideración por los migrantes para el desarrollo del proyecto migratorio. Este contexto fue favorecido por la adecuada aplicación de políticas macroeconómicas, la adopción de un tipo de cambio flotante con intervención y la confianza generada por la autoridad monetaria.

\section{Flujo migratorio}

Las evidencias anteriores forman parte del contexto general y del conjunto de indicadores que se aprecian relevantes para la adopción de un proyecto migratorio y que se ve reflejado en el flujo migratorio al Perú. Según datos de la Superintendencia Nacional de Migraciones (SNMP, 2018), se observa un incremento sostenido en el total de ingresos y salidas en el año 2018, principalmente en los meses de julio y agosto, por parte de individuos de nacio-

\section{Tabla 1}

Movimiento migratorio de venezolanos en Perú, enero-septiembre de 2018

\begin{tabular}{cccccccccc}
\hline Mes & Total & Ingresos & Salidas & $\begin{array}{c}\text { Ingresos } \\
\text { hombres }\end{array}$ & $\begin{array}{c}\text { Salidas } \\
\text { hombres }\end{array}$ & $\begin{array}{c}\text { Ingresos } \\
\text { mujeres }\end{array}$ & $\begin{array}{c}\text { Salidas } \\
\text { mujeres }\end{array}$ & $\begin{array}{c}\text { Hombres } \\
\text { total }\end{array}$ & $\begin{array}{c}\text { Mujeres } \\
\text { total }\end{array}$ \\
\hline ene-18 & 70,643 & 52,598 & 18,045 & 31,796 & 10,452 & 20,802 & 7,593 & 42,248 & 28,395 \\
feb-18 & 83,995 & 63,540 & 20,455 & 38,199 & 12,159 & 25,341 & 8,296 & 50,358 & 33,637 \\
mar-18 & 91,691 & 68,443 & 23,248 & 40,304 & 13,714 & 9,534 & 28,139 & 54,018 & 37,673 \\
abr-18 & 82,071 & 64,194 & 17,877 & 36,835 & 10,308 & 27,359 & 7,569 & 47,143 & 34,928 \\
may-18 & 87,556 & 75,579 & 11,977 & 42,417 & 6,694 & 33,162 & 5,283 & 49,111 & 38,445 \\
jun-18 & 84,013 & 69,542 & 14,471 & 39,474 & 7,991 & 30,068 & 6,480 & 47,465 & 36,548 \\
jul-18 & 100,045 & 76,913 & 23,132 & 42,385 & 12,669 & 34,528 & 10,463 & 55,054 & 44,991 \\
ago-18 & 101,798 & 78,998 & 22,800 & 41,709 & 12,469 & 37,289 & 10,331 & 54,178 & 47,620 \\
\hline
\end{tabular}

Nota. Datos tomados de Superintendencia Nacional de Migraciones Perú (SNMP, 2018). 
nalidad venezolana en Perú, como muestra la tabla 1. La normativa migratoria vinculada a venezolanos, el PTP, tuvo vigencia hasta el 31 de octubre de 2018, permitiendo una calidad migratoria de un año prorrogable para el desarrollo de actividades económicas en el marco de la legislación peruana.

\section{Venezuela, contexto 2017-2018}

Según datos del Banco Central de Venezuela (BCV, 2018), para la variable producto interno bruto (PIB), a precios constantes, se registra una disminución significativa en el periodo 20082017 (véase figura 1).

\section{Figura 1}

Venezuela: Producto Interno Bruto a precios constantes, 2008-2017

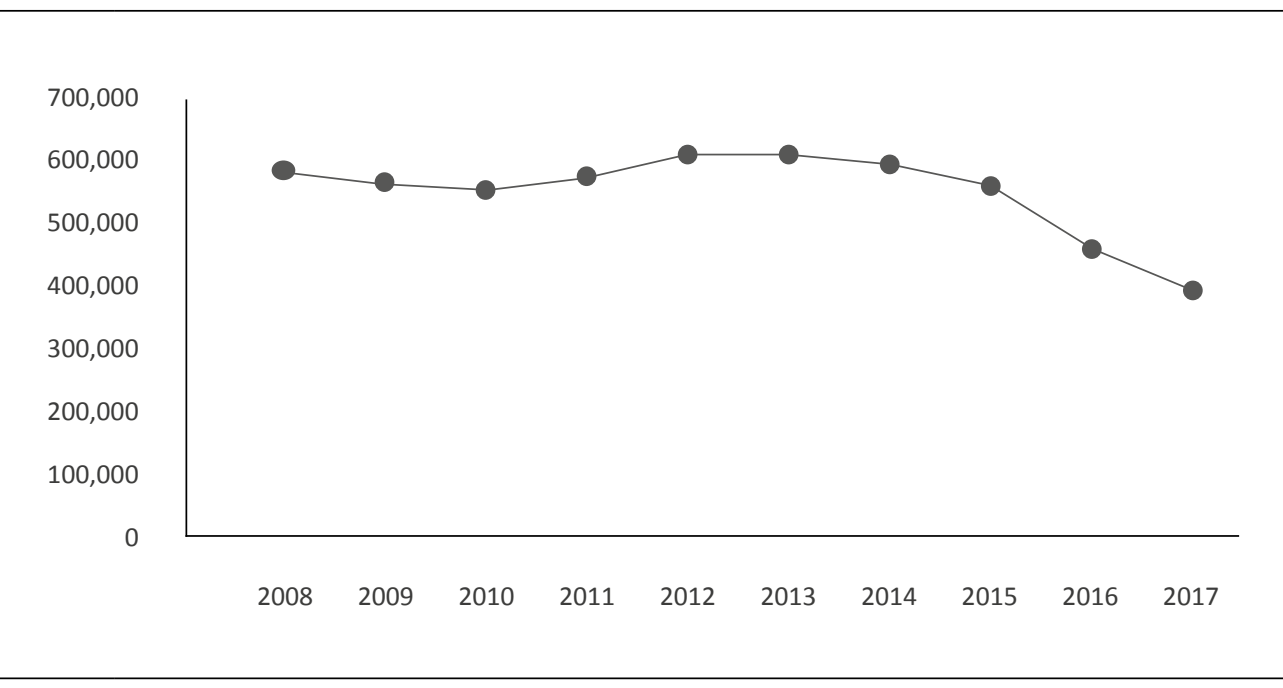

Nota. Datos tomados del Banco Central de Venezuela (BCV, 2018).

Sequín (2018) señala que la modificación del marco normativo que regula las operaciones del BCV facilitó «el financiamiento monetario del gasto del sector público» (p. 27). Asimismo, el citado autor sostiene que las reglas fiscales deben ser creíbles y «que permitan reducir el impacto de los choques externos sobre la volatilidad del producto. Aislar los gastos del sector público de las oscilaciones de los ingresos petroleros implica definir objetivos fiscales ajustados cíclicamente, combinados con un significativo fondo de estabilización» (p. 28).

Arévalo Palma, González Herrera y Peña Beltrán (2018) señalan que «el gobierno de Chávez utilizó el gasto público en obras sociales, lo que generó que el $\mathrm{BCV}$ debiera emitir más dinero 
para obtener liquidez y poder financiar su déficit público, lo cual afectó el crecimiento de la oferta monetaria» (p. 25). Este sería el factor causante de la hiperinflación.

Para protegerse del efecto hiperinflacionario, los venezolanos demandan menos bolívares (moneda local) en términos reales, ya que tratan de convertirlos en bienes, servicios, divisas $\mathrm{y}$, en última instancia, consumo prioritario de alimentos perecederos.

La desaceleración de la economía venezolana en muchos de sus sectores productivos, el incremento de los precios y las presiones sobre el tipo de cambio configuran un contexto de deterioro del bienestar social.

En materia de migración, Venezuela fue un país que, durante décadas del siglo XX, fue receptor de flujos migratorios principalmente de Europa y varias regiones de América del Sur. Esta situación ha cambiado de manera drástica. Según datos de la Organización Internacional para las Migraciones (OIM, 2018), para el mes de agosto de 2018 se contabilizaban 2.3 millones de venezolanos residentes en el extranjero. En este sentido, Bermúdez y otros (2018) señalan que el perfil del emigrante venezolano es de personas jóvenes con edades comprendidas entre 20 y 39 , mayormente hombres.

\section{Marco teórico}

En el estudio de la migración, tanto la escuela clásica como la austriaca distinguieron características y rasgos de aproximación al fenómeno migratorio, a partir de lo económico como factor de motivación. Un posible marco analítico distingue factores de atracción y expulsión. Algunas potenciales motivaciones para el migrante incluyen un entorno no agradable, leyes opresivas e impuestos altos.

Desde la visión macro del enfoque neoclásico, el individuo que emigra busca la maximización de su utilidad, valorando costos y beneficios. Desde esta perspectiva, deben tomarse en cuenta las diferencias salariales, buscando las mejores oportunidades y sopesando los beneficios y costos asociados con el traslado a la zona geográfica en cuestión (Varela Llamas, Ocegueda Hernández y Castillo Ponce, 2017). Dentro de este marco analítico, Arango (2003) hace referencia a las disparidades salariales entre los factores de producción, es decir, la desigualdad se presenta en la distribución de manera no equitativa del capital y del trabajo en un plano espacial.

En resumen, la visión macro de la teoría neoclásica relaciona los flujos internacionales migratorios con las diferencias en los mercados de trabajo y políticas públicas entre áreas geográficas.

Desde la perspectiva micro, se destaca la motivación de los individuos ante las diferencias entre regiones o países. Este marco analítico considera los ingresos esperados y los costos de movimiento. En este caso, la magnitud de la diferencia en los rendimientos determina el flujo migratorio entre países (Massey y otros, 2000).

En síntesis, la teoría neoclásica presenta dos perspectivas de explicación del fenómeno migratorio, ajustada al contexto económico de las décadas 60 y 70 . En estas perspectivas destacan rendimientos netos esperados, maximización de la utilidad, movilidad de los factores, diferencias salariales y elección 
racional del individuo (Arango, 2003; Canales, 2017; Varela Llamas y otros, 2017).

Por su parte, la nueva economía de las migraciones laborales se presenta como una crítica a la perspectiva micro de la teoría neoclásica. Viene a ser una variante que busca perfeccionar el análisis, cambiando el enfoque del análisis de la estrategia de maximización de beneficios desde el individuo hacia el hogar o la familia. Las comparaciones se realizan desde la perspectiva de la familia, considerando diversos bienes y servicios, como seguro público o privado, acceso al crédito, etc. (Massey y otros, 2000).

Sobre la nueva economía de las migraciones laborales, Arango (2003) señala dos méritos importantes. En primer lugar, esta representa una alternativa de análisis distinta a las diferencias salariales como determinantes de la migración. En segundo lugar, tiene el mérito de reconocer a las familias y hogares como fuentes diseñadoras de estrategias y de considerarlas como las unidades de análisis apropiadas para la investigación de la migración.

Otro enfoque es la teoría de mercados de trabajos duales, que toma en cuenta aspectos internos de demanda y aspectos de atracción (Massey y otros, 2000).

Otra perspectiva es la de la teoría del sistema mundial, que toma en cuenta la migración como consecuencia de las inversiones de capitalistas en los mercados en desarrollo; según esto, los movimientos migratorios serían consecuencia de la globalización económica y la transnacionalización de mercados, y los protagonistas de la emigración no son individuos, sino grupos o sectores (García Abad, 2003). Bajo este enfoque, la migración es consecuencia de un proceso de desigualdades producto de la extensión del modo de producción capitalista, en países de la periferia. En tal sentido, la inversión extranjera directa, en materias primas y tierras, contempla el cambio de procesos antiguos, de baja productividad, por procesos mucho más eficientes, lo que deviene en una reducción de mano de obra y origina un proceso migratorio (Arango, 2003).

Para el estudio del fenómeno migratorio es importante tomar en cuentas las conexiones interpersonales de migrantes y no migrantes, en el país de origen y en el país receptor, es decir, las redes migratorias. Los lazos de amistad, afinidad o parentesco, a su vez, constituyen un capital social, para tener acceso al empleo extranjero. Alcanzado cierto umbral, la expansión de la red genera una reducción de costos y riesgos para el movimiento migratorio, aumentando la probabilidad de migración (Massey y otros, 2000).

Las redes migratorias conforman un proceso dinámico de las sociedades en poblaciones de origen y llegada, por lo cual trascienden a los actores individuales. De ello deviene un concepto de cadena migratoria, referido a la transferencia de información (gestión de documentación, vivienda, gestión de viaje, financiamiento) entre familiares y amigos de los potenciales migrantes (Pedone, 2002). Estas afirmaciones permiten inferir que, dependiendo del cúmulo de información pertinente para el traslado de amigos o familiares, se toma la decisión para poder iniciar el traslado migratorio.

Otro enfoque es el de la teoría de sistemas. Este enfoque, aplicado a las migraciones internacionales, toma en cuenta la homogeneidad estructural entre regiones de proximidad geográfica (Arango, 2003). El sistema incluye distintos flujos migratorios, donde, por lo general, un 
país actúa como centro de recepción (Massey y otros, 2000).

Para el estudio del fenómeno de migración también existen enfoques cualitativos, para los cuales se aprecia gran cantidad de métodos y diseños (Crasto y Álvarez, 2017; Linares, 2016; Rubio Ros, 2013; Koechlin, Vega y Solórzano, 2018; Louidor, 2018).

\section{Método y descripción de la muestra}

Para analizar las motivaciones del flujo migratorio de venezolanos en la ciudad de Arequipa se realizó un estudio de tipo exploratorio, con diseño etnográfico. La información se obtuvo de fuentes primarias, recurriendo a entrevistas en profundidad para las que se utilizó un cuestionario con formato semiestructurado.

El cuestionario se aplicó a ciudadanos venezolanos, mayores de 18 años de edad, que emigraron a la ciudad de Arequipa. El muestreo se realizó utilizando la técnica de la bola de nieve (véase Briones, 2003). Se recogieron los relatos de 30 participantes, considerando las categorías y fases que conforman el proyecto migratorio. La entrevista fue realizada por un nacional peruano.

De la muestra total de 30 entrevistados, 16 son de sexo femenino y 14 de sexo masculino. Del total de entrevistados, 28 son de estado civil soltero (93.4\%), 14 hombres solteros y 14 mujeres solteras; 2 entrevistados son de estado civil casado. Del total de entrevistados, 18 tienen entre 18 y 30 años, y 2 tienen entre 31 y 49 años.

Las categorías utilizadas para las entrevistas se basan en las propuestas por Crasto y Álvarez
(2017) y Rubio Ros (2013), y se describen a continuación:

- Trayectoria migratoria: Motivaciones para migrar de Venezuela a la ciudad de Arequipa.

- Educación, formación y situación laboral: Nivel de formación y condiciones laborales.

- Participación en redes: Grado de vinculación, con redes de origen y destino y su influencia en la decisión para emigrar.

- Situación socioeconómica venezolana: Percepción de los principales problemas en Venezuela.

- Retorno: Expectativas de retorno a Venezuela, condiciones.

\section{Resultados}

En lo que respecta a la categoría «motivación externa», la pregunta fue la siguiente: «¿Perú formaba parte de tu proyecto para emigrar?». De los entrevistados, 10 personas tenían claro a Perú como país destino, mientras que 18 reportaron que no pensaban en emigrar, y 2 personas reportaron a Perú como escala para ir a Chile o Argentina. Los resultados sugieren que el proyecto estuvo influido por información recolectada de amigos y familiares, entre otras fuentes, y se tenía como referencia que Perú era un país tranquilo, propicio para emprender un negocio propio y realizar estudios.

Para la subcategoría de motivaciones internas propiciadoras de expulsión, las respuestas de los participantes son las siguientes: inseguridad y 
persecución, factores económicos, educación, medicina/salud, el salario no alcanzaba.

Por otro lado, como motivación externa, los entrevistados hacen referencia al colapso de servicios y de libertades económicas, por lo cual se vieron en la necesidad imperiosa de tomar la decisión. En este sentido, hubo gestión de contactos, entre familiares y amigos, como punto inicial de estrategia migratoria; luego se realizó la gestión de documentos y diversos trámites necesarios, con venta de bienes, dinero prestado o facilitado por las redes antes mencionadas. «Primero, tomar el contacto aquí en el Perú, que se encontraba mi familia, y estudiar cuáles eran las posibilidades; de llegar, qué posibilidad tenía yo. Y, después de valorar eso, decidí tomar la decisión» (entrevistado V3). «Comencé a indagar con amistades y familiares» (entrevistado V25).

Con relación a aspectos de documentación:

Desde el 2018, empecé a sacar toda mi documentación para salir, empecé a ahorrar, empecé a preparar todos mis papeles, y ya cuando vi que se estaba poniendo la cosa muy fea, le dije a mi mamá que hasta cierto día me quedaba y justamente ese día me fui. (Entrevistado V7).

En cuanto a la categoría «proyecto migratorio», se tiene la pregunta siguiente: «¿Cómo ha sido el proceso de instalación?». Respecto al proceso de adaptación, el entrevistado V5 señala una conexión previa: «Mi novia tenía aquí dos meses, se vino antes y después yo me vine. Ya ella tenía la residencia. Y cuando llegué, salí a buscar trabajo y al otro día conseguí». Por su parte, el entrevistado V22 señala ciertas trabas para adaptarse: «Me costó mucho adaptarme. Residencia fue rápido, pero empleo no».
En cuanto a la categoría «adaptación», los participantes señalan que hay relativa mejoría en lo que se refiere a bienestar, con matices de emoción por la lejanía de su entorno familiar más cercano en Venezuela. Asimismo, hay referencias a «muchas horas de trabajo», «modo de vida distinto» al de Venezuela, y expectativas de mejora en un mediano y largo plazo.

En cuanto a educación, formación y situación laboral, la mayoría de los participantes entrevistados tienen estudios de bachiller. En este sentido, la modalidad de empleo no es acorde al nivel de instrucción. Asimismo, los entrevistados perciben que la remuneración que reciben es inferior a la recibida por los nacionales. El trabajo que prevalece es el de vendedor o de atención al público. El tiempo de experiencia laboral promedio es de seis meses.

En cuanto a la situación en la ciudad de destino, la mayoría de los participantes se han adaptado a los cambios en alimentación, clima y costumbres. Para algunos es muy similar a la de Venezuela. Otros vienen de zonas donde la temperatura se parece a la estación invernal en Perú. Por el contrario, a otros les cuesta ajustarse al cambio estacional, debido a que su residencia habitual en Venezuela era de zonas de llanura donde prevalecen climas cálidos, con temperaturas promedio de $25^{\circ} \mathrm{C}$. Es decir, la adaptación varía de acuerdo con la zona de residencia del país de recepción.

Con respecto a las comidas, los entrevistados señalan de manera general que son similares, con algunas excepciones, como elementos de picante y condimentos diferentes a Venezuela. «La comida es normal, la sazón no es muy distinta, la gente no es muy diferente» (entrevistado V12) y «aquí comen muy picante, muy condimentado» (entrevistado V11). 
La comunicación con los familiares es casi a diario, para todos los participantes, salvo algunos problemas que se vienen presentando con los servicios eléctricos y de telecomunicaciones en Venezuela. Las redes sociales son medios de comunicación cotidiana (WhatsApp, Facebook, Instagram, así como también Skype). La comunicación telefónica se realiza para casos en que los familiares no estén familiarizados con las aplicaciones de redes sociales.

Visto desde la perspectiva psicológica, los sentimientos que mayormente expresan los participantes son de soledad, nostalgia y frustración; para algunos, esto se da todos los días. Algunos logran sobrellevarlo, otros manifiestan deseos de regresar. De cierta forma, siempre piensan en sus familiares. Y las condiciones que los familiares describen en la comunicación diaria llevan a comparaciones con la situación que viven en la actualidad y con la que ellos vivieron. Esto, de alguna manera, lleva a mitigar esos sentimientos, que padecen a diario.

En este sentido, el participante V11 expresa:

Por supuesto, de todo un poco, uno piensa allá... Pero uno aquí, uno vive más tranquilo. Este, sí, hay bastante nostalgia; pero, vuelvo a pensar que uno allá, vuelve otra vez, al principio: el no tener nada, otra vez con la inflación, otra vez con los problemas, pues, se le va pasando a uno.

En lo que se refiere a los trámites de legalización, los participantes no han tenido la misma oportunidad debido al vencimiento de la normativa con relación al permiso de permanencia temporal. Algunos han optado por la opción de refugiados y otros están a la espera de la reapertura del PTP.
Para finalizar el tema de la situación en la ciudad destino, la mayoría de los participantes expresan haber tenido alguna eventualidad o haber experimentado xenofobia. Ello se presenta mayormente cuando el trabajo implica contacto con el público, situación en la que se encuentra la mayoría de los participantes. «Maltrato, no. Xenofobia, sí. Sí, sí, sí. Normalmente, como a mí me toca trabajo que tengo que hablar con las personas, siempre hay esa xenofobia, "que no quiero que me atiendan"» (participante V12).

Para la dimensión «pensamiento sobre Venezuela», los participantes se orientan mayormente al concepto de familia. Tanto los establecidos, con su familia nuclear, como los solteros extrañan su entorno familiar próximo, donde se formaron y crecieron, mayormente a la madre, el padre u otro familiar.

Además del entorno familiar, algunos entrevistados asocian sentimientos de nostalgia a la cultura, la comida, el clima y otros elementos: «Todo, mi familia, la cultura, todo» (participante V9); «Por supuesto, la familia y los amigos» (participante V6); «Mis padres: si ellos se pudiesen venir para acá, excelente, pero eso es lo único que extraño en realidad, que ni siquiera la arepa» (participante V12); y «La gastronomía, la cultura, las playas, el clima» (participante V28).

En cuanto a las expectativas de volver a Venezuela, el pensamiento está presente en la mayoría de los participantes; sin embargo, quienes tienen grupo familiar se han adaptado al punto de no querer regresar. Asimismo, las condicionantes para que retornen requieren que el sistema político y económico cambie. Algunos manifiestan que podrían regresar en el corto plazo si se dieran las circunstancias. 
Otros también quisieran regresar, pero con algo de capital que les permita invertir en Venezuela.

¡Sí! Obligatoriamente tengo que volver; por lo menos tengo que reunir dinero para montar algo allá. Apenas yo tenga lo suficiente para montar cualquier negocio allá, yo me regreso, lo empiezo a montar, y así tenga que volver a regresar pa' conseguir más dinero. (Entrevistado V7).

Por lo que se refiere a la participación en redes, la mayoría de los participantes contaron con algún tipo de contacto o informante para poder tomar la decisión de migrar. En algunos casos, fueron amigos; en otros, su pareja, otros familiares, primos, tíos o padres.

En cuanto a la relación entre venezolanos y la organización de comunidades, los participantes se muestran cautelosos al momento de acercarse a algún venezolano. «Depende, por la actitud que vemos, nosotros aquí, claro, llegan muchos venezolanos, y muchos venezolanos, que quieren trabajar, vemos que están haciendo, no hacen nada, ¡eso también, eso nos causa frustración» (participante V3). «¡Muy bien! Sí, bueno, aquí uno se termina volviendo familia. Sí, no le queda de otra, porque como pasamos todo el día aquí, uno se vuelve familia» (participante V7). Y también: «He mandado pasaje a amigos para que se vengan que están mal en Venezuela y mejoren su calidad de vida» (entrevistado V21).

En este sentido, se comprende que algunos participantes tienen una percepción negativa de ciertas actitudes de sus connacionales. «Sí. El comentario, el que hace el peruano, es que te dice "tú lo conoces", porque vemos un venezolano, y lo saludamos» (participante
V8). «Mira, a mí me da pena ajena cuando veo un venezolano pidiendo, porque están mejores que uno y dejan mal el nombre de Venezuela» (participante V26). Por otro lado, el participante V4 indica lo siguiente:

Yo, como venezolana, a veces yo ando en la calle, y a veces me da..., o sea ni los miro, pero... ¿Por qué? A veces veo aquí personas adultas, trabajadores peruanos con discapacidad, trabajan. Y a veces hay muchos que vienen, puro pedir, entonces.

En cuanto al nivel de organización en comunidades o grupos, se tiene en cuenta una organización de venezolanos en Perú, de la cual se posee poca información. Así lo refiere el entrevistado V2: «Hay organizaciones, una ONG, hace falta más, organizar para que el venezolano esté más informado».

De acuerdo con los participantes, no existe una organización en comunidades, quizás por un sentimiento de desconfianza, debido a experiencias poco agradables. «Hay personas que vienen acá y no vienen a hacer cosas buenas. Entonces, quieren que los ayuden y entonces ahí es que no los ayudo. Uno al que pueda ayudar ayuda» (entrevistado V10). En efecto, en la ciudad de Arequipa, no se observa un asentamiento o comunidad de venezolanos organizados, como ha ocurrido con distintas migraciones de otras nacionalidades.

\section{Discusión}

En el presente trabajo se ha realizado una caracterización sobre el flujo migratorio de venezolanos en Arequipa, a fin de comprender las motivaciones de los proyectos migratorios de los venezolanos que emprendieron su viaje hasta Arequipa. La edad promedio de los venezolanos 
entrevistados es de 28 años, mayoritariamente de estado civil soltero, con tiempo promedio de siete meses en Arequipa, nivel de instrucción de bachiller o estudios universitarios técnicos medios, con experiencia laboral en Venezuela. Provienen de occidente y centro del país. Se han adaptado muy bien; sienten que ha habido discriminación y xenofobia, pero no de manera general. Se muestran alegres y optimistas. Por otro lado, piensan en volver tan pronto se solucionen los problemas en Venezuela.

En el proyecto migratorio, muchos venezolanos tenían ya determinado a Perú como país destino, concretamente a la ciudad de Arequipa. En este punto influye la información proveniente de un amigo, familiar o conocido, quienes, mediante comunicaciones previas, han realizado gestiones para residenciarse, aprovechar oportunidades de empleo y demás temas de interés, como informar aspectos del clima, el trato de los nacionales, xenofobia, trámites migratorios, etc.

La información que se intercambia en este tipo de red influye en la toma de decisión. Por su parte, el individuo realiza un balance del modo de vida en el país de origen, comparando con el país destino. Asimismo, en cuanto a los factores de expulsión, se detectaron como principales elementos la inseguridad y persecución, factores económicos de distinta índole, educación, medicina, salud, el salario que no alcanza; en general, un conjunto de elementos que afectan al ciudadano común y lo incitan a tomar la decisión de salir del país.

Si bien se percibe un mejor pago y mejor salario en comparación con el lugar de origen, también se observa que el salario percibido es menor que el de los nacionales.

Con respecto a las redes de migración, la mayoría de los entrevistados gestionaron contactos al inicio de la estrategia migratoria, intercambiando información con familiares y amigos, ya sea con relación a conseguir ayuda económica para poder viajar, o con relación a aspectos relevantes del lugar de destino como clima, alimentación, estado de servicios, etc.

\section{Conclusiones}

El presente trabajo se realizó con la intención de analizar las motivaciones del flujo migratorio de venezolanos en la ciudad de Arequipa, Perú. Se observa que el intercambio de información y el establecimiento de redes son elementos propiciadores de emigración.

Como factores de atracción para Perú, se observa una mejora sustantiva en el salario real recibido, superior al percibido en Venezuela, en línea con el enfoque neoclásico. Sin embargo, se verificó, mediante la información de los participantes, que el salario percibido es menor que el de los nacionales.

El proceso de evaluación por parte del grupo familiar se observó solo en los participantes que viajaron en grupo. El resto de los participantes, si bien solicitaron algunas opiniones de los demás integrantes del grupo familiar, siempre tomaron la decisión de manera individual. Es decir, existe una evaluación previa por parte del entorno familiar, con un análisis de las diferencias salariales y donde las familias y hogares pueden ser fuentes diseñadoras de estrategias.

En cuanto a las redes de migración, el contacto entre familiares y amigos como punto inicial de estrategia migratoria sugiere una propensión para la creación de redes migratorias, en coherencia con la teoría de redes migratorias y la nueva economía de las migraciones. 


\section{Referencias bibliográficas}

Arango, J. (2003). La explicación teórica de las migraciones: luz y sombra. Migración y Desarrollo, 1.

Arévalo Palma, M. E., González Herrera, Á. J. y Peña Beltrán, H. K. (2018). Efectos de pequeños y grandes especuladores sobre la tasa de cambio con base al caso venezolano 2010-2016. Universidad de La Salle, Bogotá. https://ciencia.lasalle.edu.co/finanzas_comercio/270

Armas, A. (2016). Dolarización y desdolarización en el Perú. En: G. Yamada y D. Winkelried (eds.). Política y estabilidad monetaria en el Perú. (pp. 61-94). Lima: Universidad del Pacífico.

Banco Central de Venezuela [BCV]. (2018). Producto Interno Bruto. http://www.bcv.org.ve/estadisticas/productointerno-bruto

Bermúdez, Y., Mazuera-Arias, R., Albornoz-Arias, N. y Morffe, M. (2018). Informe sobre la movilidad humana venezolana. Realidades y perspectivas de quienes emigran. Servicio Jesuita a Refugiados; Universidad Católica del Táchira; Universidad Simón Bolívar.

Briones, G. (2003). Métodos y técnicas de investigación para las ciencias sociales. Trillas.

Canales, A. I. (2017). La migración internacional en los modelos neoclásicos. Una perspectiva crítica. Huellas de la Migración, 2(3), 11-36.

Carassou, R. H. (2006). La perspectiva teórica en el estudio de las migraciones. Siglo Veintiuno Editores.

Chacaltana, J. (2016). Perú, 2002-2012: crecimiento, cambio estructural y formalización. Revista Cepal (119), 47-68.

Crasto, T. C. y Álvarez, M. R. (2017). Percepciones sobre la migración venezolana: causas, España como destino, expectativas de retorno. Migraciones. Publicación del Instituto Universitario de Estudios sobre Migraciones (41), 133-163.

ENCOVI. (2017). Encuesta de Condiciones de vida de Venezuela. Caracas: Universidad Andrés Bello, Universidad Central de Venezuela, Universidad Simón Bolívar. https://www.ucab.edu.ve/wp-content/uploads/ sites/2/2018/02/ENCOVI-2017-presentaci\%C3\%B3n-para-difundir-.pdf

Garavito, C. y Muñoz, I. (eds.) (2012). Empleo y protección social. PUCP.

García Abad, R. (2003). Un estado de la cuestión de las teorías de las migraciones. Historia Contemporánea, 26, 329-351.

Gutiérrez, A. P. y Pérez, F. (2018). Choques agregados y sectoriales en la economía peruana. Revista Estudios Económicos, Banco Central de Reserva del Perú (35), 29-53.

Izquierdo Escribano, A. (2000). El proyecto migratorio de los indocumentados según género. Papers: Revista de sociología (60), 225-240. 
Koechlin, J., Solórzano, X., Larco, G. y Fernández-Maldonado, E. (2019). Impacto de la inmigración venezolana en el mercado laboral de tres ciudades: Lima, Arequipa y Piura. https://www.uarm.edu.pe/FondoEditorial/eticadesarrollo/inmigraci\%C3\%B3n-venezolanos-mercado-laboral-tres-ciudades-lima-arequipa-piura

Koechlin, J., Vega, E. y Solórzano, X. (2018). Migración venezolana al Perú: proyectos migratorios y respuesta del Estado. El éxodo venezolano: entre el exilio y la emigración, 47.

Lewis, A. (1954). Economic development with unlimited supplies of labour. Manchester School of Economic and Social Studies, 22, 139-191.

Linares, M. D. (2016). Trayectorias migratorias e inserción laboral de migrantes recientes en Santa Rosa-Toay (La Pampa, Argentina). Pilquen-Sección Ciencias Sociales, 19(4), 2.

Louidor, W. E. (2018). La migración forzada venezolana a Colombia (2015-2018): de una revisión documental a los esbozos de un análisis coyuntural y estructural. En: J. Koechlin y J. Eguren (eds.) El éxodo venezolano: entre el exilio y la emigración. Lima: Universidad Antonio Ruiz de Montoya; Konrad Adenauer Stiftung; OIM; OBIMID.

Massey, D., Arango, J., Graeme, H., Kouaouci, A., Pellegrino, A. y Taylor, J. E. (2000). Teorías sobre la migración internacional: una reseña y una evaluación. Trabajo, 2(3), 5-50.

Organización Internacional para las Migraciones [OIM]. (2018). Tendencias Migratorias Naciones del Sur. https:// robuenosaires.iom.int/tendencias-y-datos-relevantes

Pedone, C. (2002). El potencial del análisis de las cadenas y redes migratorias en las migraciones internacionales contemporáneas. Paper presentado en las Actas del III Congreso sobre la inmigración en España. Contextos y alternativas.

Pérez, F., Quispe, Z. y Rodríguez, D. (2016). El proceso de institucionalización de la autonomía del Banco Central de Reserva del Perú. En: G. Yamada y D. Winkelried (eds.). Política y estabilidad monetaria en el Perú. (pp. 37-60). Lima: Universidad del Pacífico.

Rossini, R. (2016). La política monetaria del Banco Central de Reserva del Perú en los últimos 25 años. En: G. Yamada y D. Winkelried (eds.). Política y estabilidad monetaria en el Perú. (pp. 23-35). Lima: Universidad del Pacífico.

Rubio Ros, C. (2013). Londres, tierra prometida: la emigración de jóvenes titulados universitarios catalanes a Londres. Perifèria: revista de recerca i formació en antropologia, 18(2), 0158-0174.

Sequín, L. Z. (2018). El petróleo y la política fiscal en Venezuela.

Superintendencia Nacional de Migraciones [SNMP] (2018). Evolución mensual movimiento migratorio peruano. Boletines. Instituto Nacional de Estadística e Informática (INEI). https://www.inei.gob.pe/biblioteca-virtual/ boletines/migraciones/1/

Varela Llamas, R., Ocegueda Hernández, J. M. y Castillo Ponce, R. A. (2017). Migración interna en México y causas de su movilidad. Perfiles Latinoamericanos, 25(49), 141-167. 